\title{
COVID19-Global: A shiny application to perform a global comparative data visualization for the SARS-CoV-2 epidemic
}

\author{
Aurelio Tobías ${ }^{1}$, Pau Satorra ${ }^{2}$, Joan Valls ${ }^{3}$, Cristian Tebé ${ }^{2}$ \\ (equal contribution)
}

1. Institute of Environmental Assessment and Water Research (IDEA), Spanish

Council for Scientific Research (CSIC), Barcelona, Spain.

(aurelio.tobias@idaea.csic.es)

2. Biostatistics Unit, Institut d'Investigació Biomèdica de Bellvitge (IDIBELL), Barcelona, Spain.

3. Department of Mathematics, Universitat Autònoma de Barcelona (UAB), Bellaterra, Barcelona, Spain.

(Version 1.0 - Date: May $\left.17^{\text {th }}, 2020\right)$

\begin{abstract}
Data visualization is an essential tool for exploring and communicating findings in medical research, especially in epidemiological surveillance. The COVID19-Global online web application systematically produces daily updated data visualization and analysis of the SARS-CoV-2 epidemic on a global scale. It collects automatically daily data on COVID-19 diagnosed cases and mortality worldwide from January $1^{\text {st }}, 2020$ onwards. We have implemented comparative data visualization between countries for the most common indicators in epidemiological surveillance to follow an epidemic: attack rate, population fatality rate, case fatality rate, and basic reproduction number. The application may help for a better understanding of the SARS-CoV-2 epidemic worldwide.
\end{abstract}


medRxiv preprint doi: https://doi.org/10.1101/2020.05.18.20105684; this version posted May 22, 2020. The copyright holder for this preprint (which was not certified by peer review) is the author/funder, who has granted medRxiv a license to display the preprint in perpetuity.

All rights reserved. No reuse allowed without permission.

\section{INTRODUCTION}

The first confirmed case of SARS-CoV-2 in China was reported to the WHO country office in China on December 315t 2019 (1). The outbreak was declared a public health emergency of international concern on January $30^{\text {th }}, 2020$ (1). Since then, 215 countries have been affected worldwide, 4,722,233 people have been diagnosed cases, and 313,266 have died due to the SARS-CoV-2 pandemic (2).

Data visualization and analysis is an essential tool for exploring and communicating findings in medical research, and especially in epidemiological surveillance (3). It can help researchers and policymakers identify trends that could be overlooked if the data were reviewed in tabular form. We have developed a Shiny application to compare epidemiological indicators on the SARS-CoV-2 epidemic.

\section{SOFTWARE AVAILABILITY AND REQUIREMENTS}

The COVID19-Tracker app has been developed in RStudio (4), version 1.2.5033, using the Shiny package, version 1.4.0. Shiny offers the ability to develop a graphical user interface (GUI) that can be run locally or deployed online. Last is particularly beneficial to show and communicate updated findings to a broad audience. All the analyses have been carried out using R (5), version 3.6.3.

The application has a friendly structure based on menus to shown data visualization for the most common indicators in epidemiological surveillance to follow an epidemic: attack rate, population fatality rate, case fatality rate, and basic reproduction number (Figure 1). 


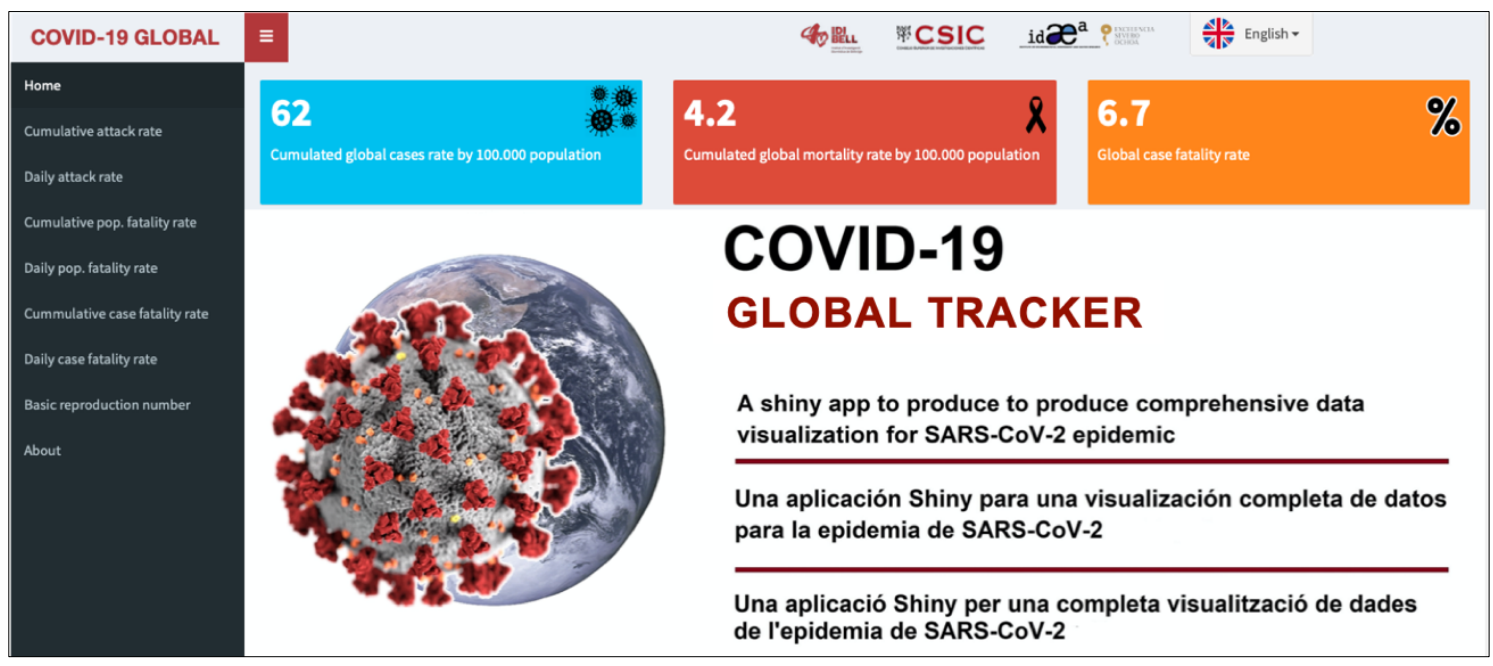

Figure 1. Home page of the COVID19-Global application, for visualization and analysis of data from the SARS-CoV-2 worldwied. Available at: https://ubidi.shinyapps.io/covid19global/

Two additional menus are already implemented to describe the epidemiological indicators analyses and collecting other applications, also developed in Shiny, by other users to follow the COVID19 epidemic globally.

The app has an automated process to update data and all analyses every time a user connects to the app. It is available online at the following link: https://ubidi.shinyapps.io/covid19global/ and shortly free available on Github as an R package. The application allows comparing epidemiological indicators between countries on the current date or since the start of the epidemic in each country. The displayed graphs are mouse-sensitive, showing the observed and expected number of events through the plot. The graphs can also be displayed on a log scale. Likewise, when selecting any plot, the application allows the option of downloading it as a portable network graphic (*.png). All menus are available in English, Spanish, and Catalan.

\section{DATA SOURCES}

We collected daily data on COVID-19 diagnosed cases and mortality, from January $1^{\text {s, }}$ 2020, onwards. Data is collected automatically from the ECDC's (European Centre for Disease Prevention and Control) the geographical distribution of COVID-19 cases worldwide (6). The downloadable dataset is updated daily and contains the latest available public data on COVID-19 worldwide. 
medRxiv preprint doi: https://doi.org/10.1101/2020.05.18.20105684; this version posted May 22, 2020. The copyright holder for this preprint (which was not certified by peer review) is the author/funder, who has granted medRxiv a license to display the preprint in perpetuity.

All rights reserved. No reuse allowed without permission.

\section{METHODS}

We have implemented a data visualization for the following epidemiological indicators:

The attack rate is the ratio between the positively diagnosed cases $(T+)$ and the total population $(P)$ in a given country $(A R=C+/ P)$.

The population fatality rate is the ratio between the positively diagnosed deaths (D+) and the population $(P)$ in a given country $(P F R=D+/ P)$.

The case fatality rate is the ratio between the positively diagnosed deaths $(D+)$ and the positively tested cases $(C+)$ in a given country $(C F R=D+/ C+)$.

The basic reproduction number $\left(\mathrm{R}_{0}\right)$ is the average number of secondary cases of disease caused by a single infected individual over his or her infectious period (7). Here, we used the R package EpiEstim to estimate the $\mathrm{R}_{0}(7)$.

Figure 2 shows an example of these indicators comparing the six most affected countries worldwide (United States, Russia, Brazil, Spain, United Kingdom and Italy up to May $17^{\text {th }}, 2020$ ) since the epidemic started in each country. 


\section{a) Attack rate (AR)}

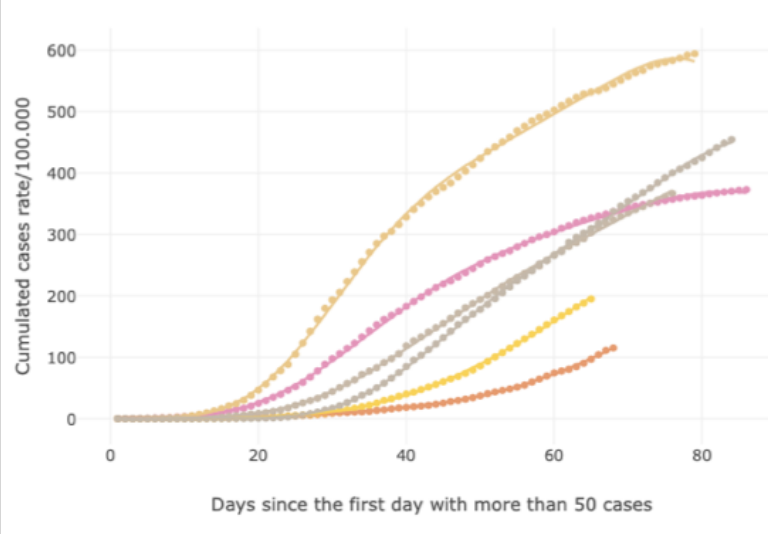

c) Case fatality rate (CFR)

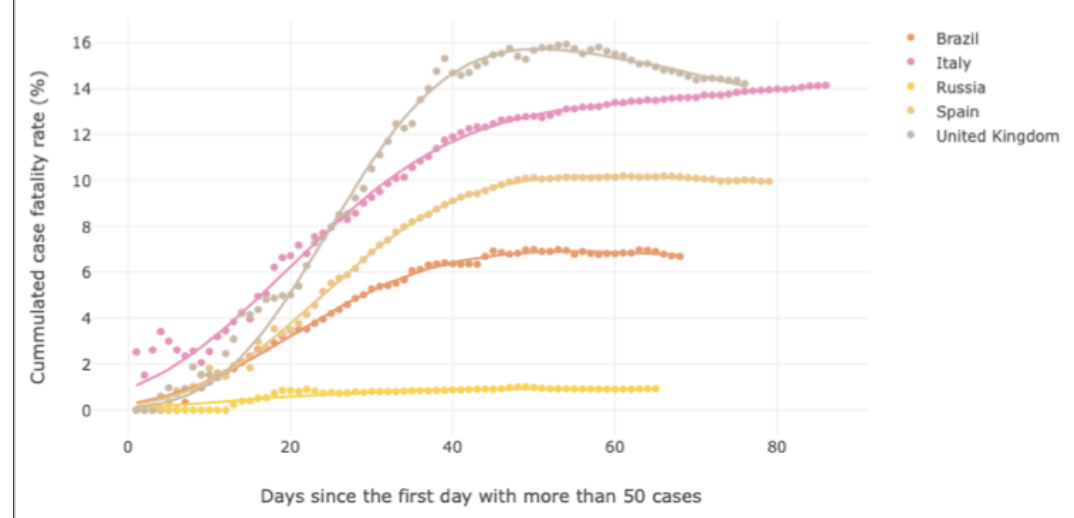

b) Population fatality rate (PFR)

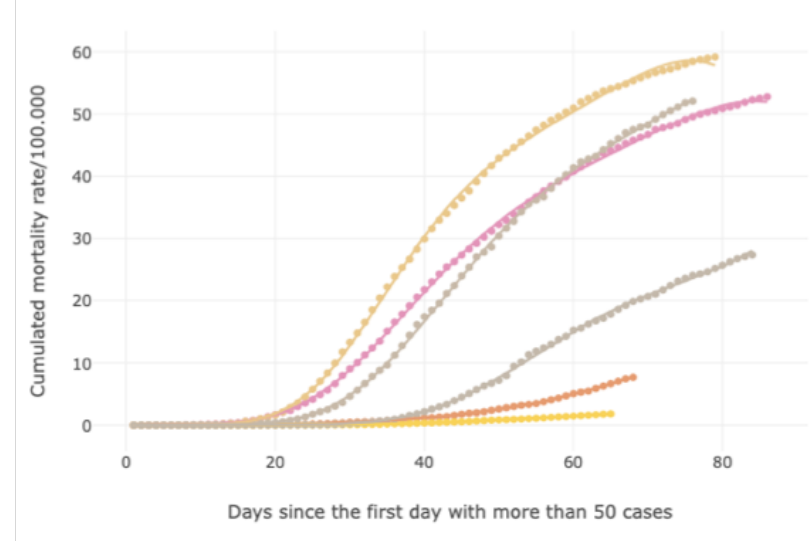

: Brazil

- Italy
$:$ Russia
Spain

:- Spain

- United States of America

d) Basic reproduction number $\left(R_{0}\right)$

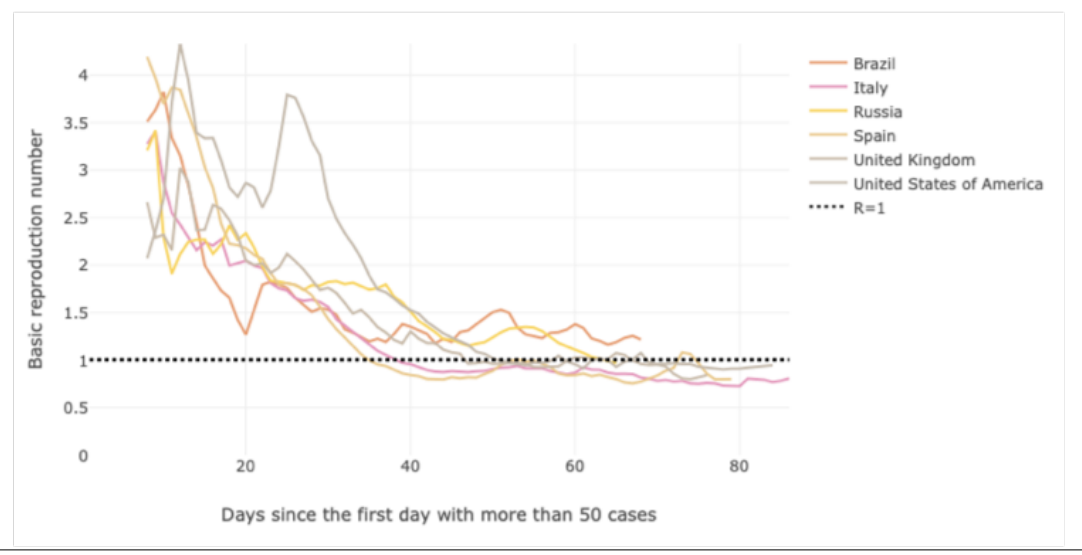

Figure 2. Standard output display of the COVID19-Global application (results updated to May $17^{\text {th }}$, 2020) for the attack rate (a), population fatality rate (b), case fatality rate (c), and basic reproduction number $\left(R_{0}\right)$, for the six countries wit the largest number of diagnosed cases (United States, Russia, Brazil, Spain, United Kindom and Italy). 
medRxiv preprint doi: https://doi.org/10.1101/2020.05.18.20105684; this version posted May 22, 2020. The copyright holder for this preprint (which was not certified by peer review) is the author/funder, who has granted medRxiv a license to display the preprint in perpetuity.

\section{DISCUSSION}

Disease surveillance forms the basis for response COVID-19 epidemic and requires knowing trends in disease frequency in different subgroups and locations. The COVID19-Global application provides a global overview for the epidemiological surveillance of the pandemic worldwide, visualizing in a simple and intuitive way the main epidemiological indicators of all countries affected by the SARS-CoV-2 pandemic with daily updated data.

Country comparisons based on counts and their trends across populations and places should be replaced by rate comparisons adjusting the count to the size of the population (8). However, we should acknowledge that it is not possible to make an accurate estimate of the rates due to the underreporting of diagnosed cases and mortality in official statistics (9). Moreover, the application does not take into account the changes in the definition of diagnosed cases, nor the lockdown measures are undertaken in each country, aiming to flatten the curve. Moreover, the selection of the number of people who have been tested is critical for an accurate estimation (8). Accurate estimation of the rates depends on the testing strategy, the prevalence of infection, and the test accuracy. Differences between countries or overtime may merely reflect differences in selection for testing and test performance (8). In any case, a routine health system data of basic epidemiological indicators for the SARS-CoV-2 pandemic allowing for the comparison between countries, is essential for surveillance epidemiology and health policy.

We continue to plan improvements to the application to include specific data visualizations by country and aggregated by geographical regions. In summary, this application, easy to use, comes to fill a gap in this particular scenario for the visualization of epidemiological data for the COVID-19 at a global scale. 
medRxiv preprint doi: https://doi.org/10.1101/2020.05.18.20105684; this version posted May 22, 2020. The copyright holder for this preprint (which was not certified by peer review) is the author/funder, who has granted medRxiv a license to display the preprint in perpetuity.

All rights reserved. No reuse allowed without permission.

\section{Funding}

None.

\section{Acknowledgements}

None.

\section{Conflict of interest}

None. 
medRxiv preprint doi: https://doi.org/10.1101/2020.05.18.20105684; this version posted May 22, 2020. The copyright holder for this preprint (which was not certified by peer review) is the author/funder, who has granted medRxiv a license to display the preprint in perpetuity.

\section{References}

1. World Health Oorganization. Rolling updates on coronavirus disease (COVID-19). Updated 13 May 2020. WHO, Geneva. [Accessed: May 17th 2020 ]. Available from: https://www.who.int/emergencies/diseases/novel-coronavirus-2019/events-asthey-happen

2. Ourworld in Data. Coronavirus Disease (COVID-19) Statistics and Research. Oxford. Martin School, The University of Oxford, Global Change Data Lab; 2020. [Accessed: May $\left.17^{\text {th }}, 2020\right]$. Available from: https://ourworldindata.org/coronavirus/

3. Carroll LN, Au AP, Detwiler LT, Fu TC, Painter IS, Abernethy NF. Visualization and analytics tools for infectious disease epidemiology: a systematic review. J Biomed Inform. 2014;51:287-98.

4. Team R. RStudio: Integrated Development for R. RStudio, Inc. Boston, MA; 2015.

5. Team R. R: A language and environment for statistical computing. R Foundation for Statistical Computing, Vienna, Austria; 2020.

6. European Centre for Disease Prevention and Control. Download today's data on the geographic distribution of COVID-19 cases worldwide Stockholm. Accessed: May $\left.17^{\text {th }}, 2020\right]$. Available from: https://www.ecdc.europa.eu/en/publicationsdata/download-todays-data-geographic-distribution-covid-19-cases-worldwide/

7. Cori A, Ferguson NM, Fraser C, Cauchemez S. A new framework and software to estimate time-varying reproduction numbers during epidemics. Am J Epidemiol. 2013;178(9):1505-12.

8. Pearce N, Vandenbroucke JP, VanderWeele TJ, Greenland S. Accurate Statistics on COVID-19 Are Essential for Policy Guidance and Decisions. Am J Public Health. 2020:e1-e3.

9. Battegay M, Kuehl R, Tschudin-Sutter S, Hirsch HH, Widmer AF, Neher RA. 2019novel Coronavirus (2019-nCoV): estimating the case fatality rate - a word of caution. Swiss Med Wkly. 2020;150:w20203. 